\title{
Visualized System Dynamics Models as Information and Planning Tools
}

\author{
Hanne-Lovise Skartveit, Katherine Goodnow and Magnhild Viste \\ University of Bergen, Norway
}

\section{hanne-lovise.skartveit@media.uib.no katherine.goodnow@media.uib.no magnhild@ifi.uib.no}

\begin{abstract}
In this paper, we describe the use of visualization of system dynamics models as client information and management tools. System dynamics is a methodology for analyzing and understanding how complex systems change over time. System dynamic models have been developed for a broad range of information to client applications - from resource management problems to the mapping of stocks and flows on factory floors. The problem faced by many users of system dynamic models is their graphic complexity for users not trained in the field. This paper addresses new research into visualization of system dyna mics models to make client information more efficient and accessible. This research involves the use of narrative, video and sound embedded in statistical material. This paper also considers one particular client group - that of politicians, planners and civil society in developing countries.
\end{abstract}

Keywords : Client Information, Resource Management, System Dynamics, Video Visualization, Simulation

\section{Introduction}

Researchers at the Department of Media Studies, the Department of Information Science and InterMedia at the University of Bergen have been developing, in collaboration, visualized system dynamics models. These models are aimed for use by clients, particularly economic or human resource planners, and can be used either as collaborative or single- user tools. System dynamic models have been developed for a broad range of applications - from environmental planning to factory floors. The problem faced by many users of system dynamics models is their graphic complexity for users not specifically trained within the field. The VOCS (Visualization of Complex Systems) project in Bergen, Norway is addressing this problem through the development of multimedia applications allowing enhanced client information and therefore new avenues for use - including urban and ecological planning in developing countries. The VOCS project collaborates in this manner with the IDSC (Information and Decision Support Center, The Cabinet) in Cairo, Egypt, and the Millennium Institute in Washington and has developed prototypes on cultural heritage sites such as the historic city of Quito, Ecuador.

\section{What Is System Dynamics?}

Material published as part of these proceedings, either on-line or in print, is copyrighted by Informing Science. Permission to make digital or paper copy of part or all of these works for personal or classroom use is granted without fee provided that the copies are not made or distributed for profit or commercial advantage AND that copies 1) bear this notice in full and 2) give the full citation on the first page. It is permissible to abstract these works so long as credit is given. To copy in all other cases or to republish or to post on a server or to redistribute to lists requires specific permission from the publisher at Publisher@InformingScience.org
System dynamics is a methodology for analyzing and understanding how complex systems change over time. It can deal with questions such as "What produces conflicts within a family or community?" or "How could human population growth in the Galapagos influence the fragile ecology of the islands?" The field of system dynamics was founded by Jay W. Forrester at MIT in the 1960s. System dynamics study the interde- 
pendence of the different variables of a system, and how problem behavior could be understood and predicted by exploring a system's underlying structure. The systems and problems that are analyzed in system dynamics are built as models on a computer. The computer models can treat complex quantified information and run simulations based on simultaneous calculations. By changing variables, the user can experiment with the model and experience different simulation outcomes (see Forrester, 1961; Sterman, 2000).

Although traditional media productions may capture elements of natural and social development as well as the underlying causal structure, such productions do not often match well the complexity of this structure and typically does not explain well how such a structure produces the development observed.

Therefore, we design system dynamic based multimedia environments that allow for the presentations of the relationship between the underlying structure and the resulting behavior of natural and social systems in the form of narratives produced and presented on demand.

The purpose of such multimedia productions is to outline and illustrate insights gained into sustainable and non-sustainable operating conditions in natural and social systems. Moreover, the purpose is for our target audience to "experience" how these conditions of sustainability change in response to various policies and implied decisions suggested and employed by that audience - the client. In other words, we will not only recreate history, but also allow for multimedia based scenario analyses.

For that purpose, we are developing methods, techniques and tools for producing non-linear, interactive learning environments (ILEs) or single-user, client-information environments that utilize existing and new media material for the purpose of knowledge dissemination particularly in the area of sustainable development. Such ILEs and client-information environments must exhibit a variety of natural and social developments over time in response to various actions taken by the audience and must point to the underlying structural reasons for success or failure in the management of such complex, dynamic systems.

The theoretical foundation for our work in this project is system dynamics, a field of research whereby we study complex, dynamic natural and social systems by way of modeling and simulation. We utilize system dynamics in the following ways to facilitate the development of interactive multimedia productions on a variety of topics:

1. Within the field of system dynamics a large body of models has been developed. Existing system dynamics models can contribute with distilled domain expertise in a variety of fields, including sustainable development. Classic models resulting from expert group modeling can then be drawn upon and modified for other case studies and clients.

2. System dynamics offer a number of graphical ways to represent structure, all centered around the integration (accumulation) processes that causes systems to behave dynamically and the causal relationships that determine specifically how such systems behave. These structural maps constitute a framework for multimedia presentations of system structures. Moreover, they allow for efficient navigation within such structures.

3. System dynamics also offer a variety of ways to represent system development, i.e. system beha vior, over time by way of simulation. That is to say, simulation results in a narrative laid out on a storyboard that constitutes the foundation for automatic screen writing calling for on-demand multimedia presentations triggered conditionally as the simulation evolves. A simulation may evolve very different if the initial conditions or the interventions applied during the simulation change. The implication is that the story told may change path allowing for conditional branching by way of the underlying simulation engine that drives the multimedia production through time.

4. System dynamics offer an analysis of the behavior of the system under investigation that allows us to link the behavior observed to the underlying system structure. The implications are threefold: 
(a) We may identify the underlying structural components of the system that at any point in time, governs the behavior observed. This enables us to focus our explanation to clients regarding systems behavior by referring to the specific underlying structural causes of that behavior.

(b) We may interrelate the various aspects of the system development, each characterized by the dynamic behavior of a particular system attribute. This enables us to trace the origin of a particular development back in time or, in the reverse, build a story that leads up to the current state of affairs. This allows clients to understand the information passed on at a deeper level.

(c) We may highlight accessible points of intervention in the system structure, - those that may be used as leverage points to modify the system behavior. This allows us to offer entry point for decision-making and even policy design for the purpose of systems management, - a prerequisite to the introduction of interactivity in multimedia productions and a prerequisite for clients to be able to make informed decisions.

5. System dynamics has a number of modeling and simulation technologies to offer. Some of them are geared towards systems analysis, others at knowledge dissemination. Power $\operatorname{sim}^{\mathrm{TM}}$ is a soft ware that combines these characteristics with ease of use and is used predominantly in the VOCS project. As an example of one application, we are currently engaged in a collaboration on SD applications for multimedia with IDSC (Information and Decision Support Center, The Cabinet), Egypt, in which we address the conditions for sustainable development in Egypt. The Egyptian and Ecuadorian models will be returned to after a further introduction to visualized system dynamics models for client information and resource management.

\section{Simulation and Visualization}

A simulation could be described as a simplified representation of a system. Simulations are rule based. In the modeling process one tries to find the behavioral rules underlying the system that is being modeled. The learning process occurs through interaction with the underlying model. A simulation where the underlying model is hidden and the user's goal is to discover it independently through research is called a "black box simulation" (Alessi, 2001). In simulation games the pleasure of the game is precisely the pleasure of deconstruction, the pleasure of figuring out its underlying rules (Frasca, 2001).

The game industry provides interesting examples of visualization of simulation models. Electronic Arts' SimCity series (1996 - 2002) is an example of a commercial simulation game inspired by the theories of system dynamics. Will Wright, the game's author, discovered Jay W. Forrester's computer models on urban growth and stagnation (Forrester, 1969), and used his theories in the development of the game's underlying simulation model (Pearce, 2002). While system dynamics simulation modeling software such as Powersim or STELLA generate equations, graphs and tables to illustrate the behavior of the system, SimCity illustrates behavior in a more engaging way through on-the-fly generated animation of cars and building construction.

The game development community represents cutting edge research and development of computer based visualization, applied AI, overall interface design, persistent worlds, network interaction, and other building blocks that will improve next-generation models and simulation (Sawyer, 2002). The Foresight and Governance project at Woodrow Wilson International Center for Scholars recently initiated a research project to encourage partnerships between the commercial game industry and public policy groups or institutions to build models and simulations for non-entertainment purposes. SimHealth and Virtual $U$ are existing examples of such collaboration projects. SimHealth is a simulation of the U.S. healthcare system. This management game was created in 1993 as a result of the Markle Foundation working with SimCity developer Will Wright and his company Maxis (Electronic Arts). In 2000, the Alfred P. Sloan Foundation released Virtual $U$, a computer simulation of university management in game 
form. Virtual $U$ is being used to train higher-education administrators and managers and to research university management economic strategies (Sawyer, 2002).

For clients, one of the drawbacks of such projects is the cost involved. Sawyer (2002) estimates that the costs of a game project developed by professional designers and modelers can be anywhere from US $\$ 500,000$ - US $\$ 10,000,000$, depending on purpose, user platform and overall complexity. The sheer modeling process, system dynamics modeling included, is always cost and resource demanding. Adding interface and game design dramatically increases the costs. However, the costs of visualization must be weighed against the need for accessible and understandable models. Furthermore, if open-source systems or modeling software with visualization features included is developed, this would reduce costs and allow a wider range of clients to develop their own visualized models. The prototypes designed in the VOCS project explore visualization tools that may at a later stage be included as an integrated part of Powersim software.

Other examples of visualized simulation models and system dynamic models are less high-tech, but yet worth studying. Several examples of system dynamics board games exist. One of the most famous is The Beer Distribution Game (Sterman, 1989). The game represents the supply chain of a typical manufacturing industry, consisting of a retailer, wholesaler, distributor and factory. Each player is responsible for one sector and during the game session they typically experience the consequences of delay in a supply chain (Sterman, 2000). Another example of a system dynamic board game is the Operations Excellence Game developed by Ledet Enterprises. Through playing, employees at all levels are intended to achieve a deeper understanding of their organization's internal workings and structure. The game has been used by British Petroleum as a means to inspire employees to internal commitment (Monus, Kuenzli \& Griffith, 2000).

Most existing system dynamic models are presented by equations, stock- and flow diagrams, and simple graphs, which make a thorough understanding of the system difficult to acquire even for experienced mathematicians and system thinkers (Moxnes, 2000; Sterman, 1989, 2002). Stud ying game design may help designers to think of ways to make system dynamics and other simulation models engaging and comprehensible also for non-expert users and clients. Alessi (2000) recommends using existing authoring software in combination with system dynamics software to provide better user interfaces and instructional support. In the following, through the presentation of three different prototypes, we describe possible methods for developing system dynamics models enhanced with visualization.

\section{The Two-Shower Model}

As a generic example of the type of visualizations that is carried out in the VOCS-project, the "twoshower model" is a useful introduction. The system dynamics model itself was originally presented in Morecroft, Larsen, Lomi, \& Ginsberg, (1995). The model has been further deve loped and visualized by the VOCS research team at the University of Bergen (UiB) including Skartveit, Viste, Kastet, Davidsen and Goodnow. This particular model was chosen for visualization because it is often used in teaching as an introduction to the field of system dynamics. Within system dynamics, water and pipes are often used as metaphors to describe the dynamic elements of a system. System elements may be described as flows of water (in a population model this would be birth- and death rate), valves controlling the flow (variables such as access to health and education), and the water level of a basin (total population) changing according to the in- and out-flows.

The Two-Shower model has few variables, but illustrates some basic and central system dynamics principles. The simplicity of the model also made it suitable as case for a first video visualization experiment. In the model, two persons, unaware of each other, share the same hot tank for showering. The model as such is a metaphorical model for more complex organizational resource sharing. The simulation of the model illustrates the causes and consequences of interdependence in resource allocation and 
is useful for clients to understand interdependence. The model, fully developed, is useful for management games and can be altered to fit client profiles or particular client problems in relation to resource allocations and managements.

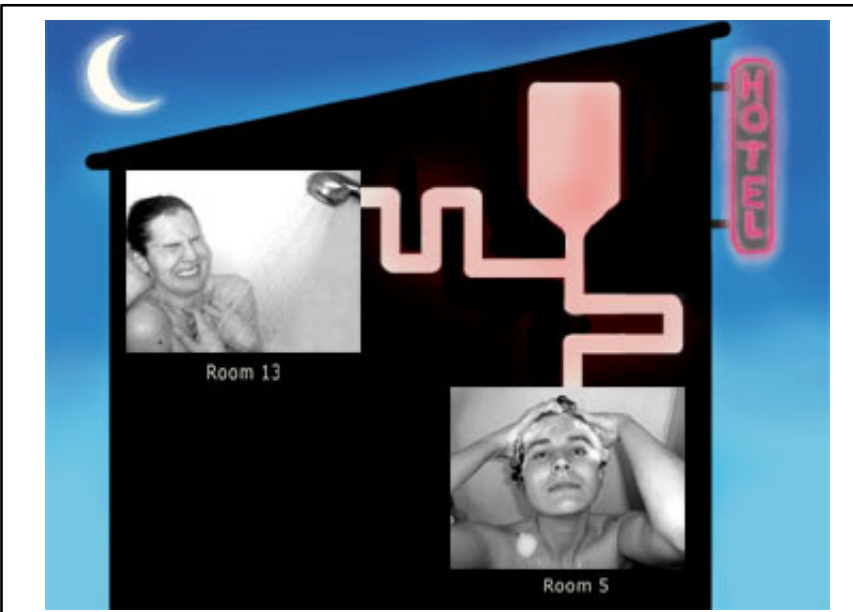

Figure 1: Opening interface

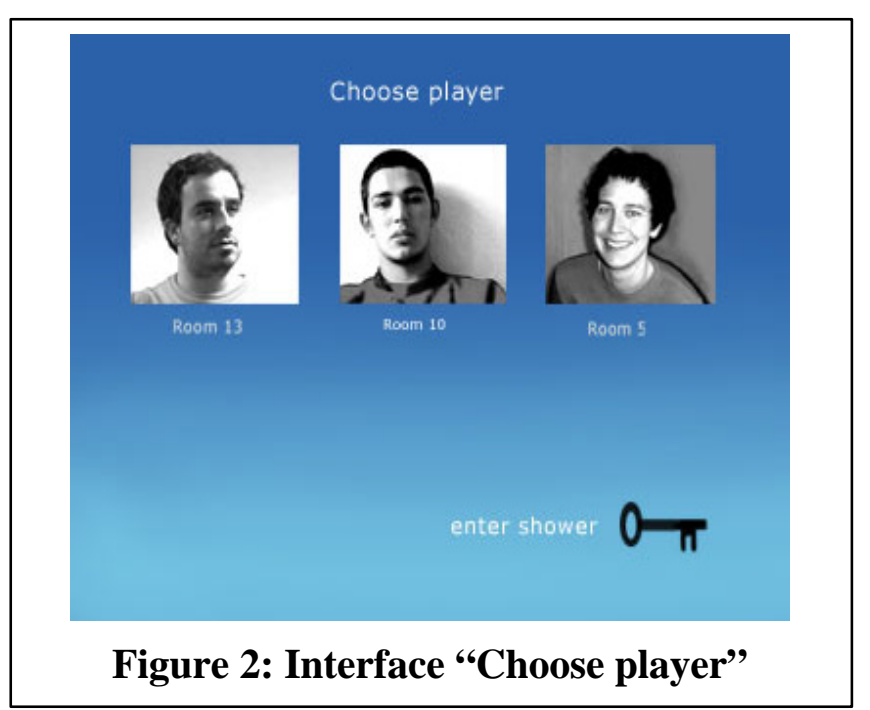

Figure 2: Interface "Choose player”

To understand this generic model more graphically, imagine the following scene: You arrive at a new hotel for the night, and, tired from an exhausting journey you long to take a refreshing shower. The bathroom looks OK and the shower as well - until you turn on the water. You struggle to find the right temperature, turning the tap more and more desperately towards hot or cold with no immediate results. Finally, you may realize that a little patience waiting for the temperature change, before you turn on even more hot or cold water, helps more than cursing. Then you hear the shower in the neighbor room being turned on, and it is the same story all over again. What happened?

Within the opening interface (Fig. 1), the problem-scenario is presented: two persons sharing the same hot water tank are taking a shower in a hotel, but none of them manages to find the right temperature. In the two 'windows' of the hotel, the user/ client sees sequences of still pictures or video clips from the showers. The video images are triggered by the underlying model and change along with the shower temperature in the simulation.

When the user has run the demonstration, she will be asked if she wants to try herself and her role will then be changed from observer to player. Before entering the shower, the user can choose which hotel guest she wants to be (Fig.2). The choose-player device is taken from PC games and is intended to cre-

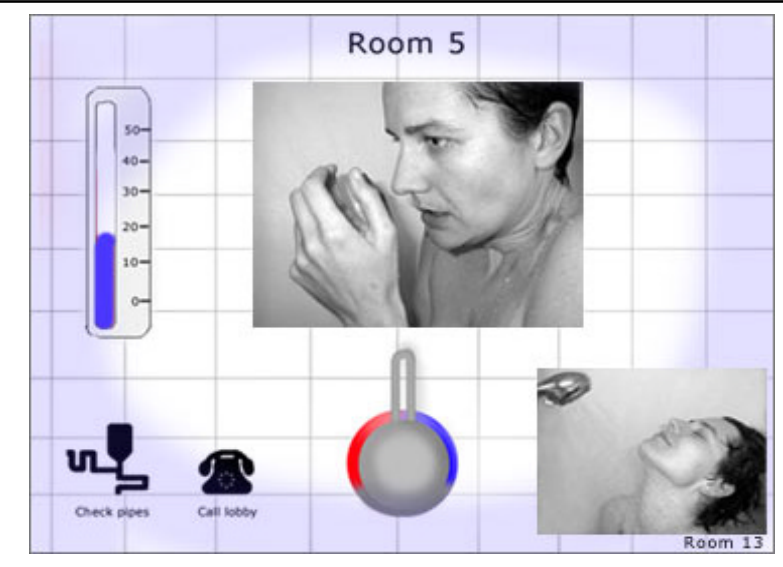

Figure 3.1: Too cold showertemperature

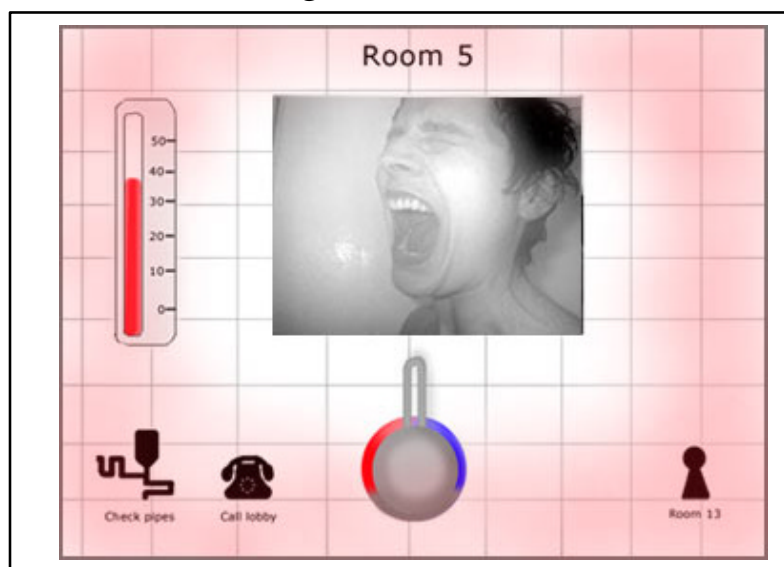

Figure 3.2: Too hot shower temperature 
u도

By clicking the pipes-icon the user will receive an animated explanation of how the pipes or the pipe system work.

3 By clicking the telephone-icon, the user will hear a sound file from a phone conversation between a frustrated guest and the receptionist, explaining why the water is too hot or too cold.

$\boldsymbol{1}$ By clicking the keyhole icon, the user can see what is going on in the shower in the other hotel room.

\section{Figure 3.3: Explanation of interface icons}

ate identification with the character on screen.

As the user manipulates the temperature tap, the behavior of the system is illustrated with changing pictures/ video sequences, colors and animation (Fig. 3.1, 3.2 and 3.3):

One of the critical problems will be to perceive what it is that the user or client has not understood, and display information accordingly.

\section{Use of Video Images in the Shower Model}

Video images play an important role in the visualization of the system behavior and allow the user to monitor the changing conditions of both showers. The underlying simulation model (and the user's interaction with it) generates short real-time (if the simulation is run in real-time) video sequences representing the actual conditions of the system. The video sequences will run in a window(s) during simulation. The sequences will be composed by a combination of short clips from a library: close-ups of hand turning up or down the hot water, water streaming from the showerhead, faces with varying expressions, screaming mouth, jumping feet etc. The images are accompanied by sounds of screams and running water. How the video clips are combined depends upon the client's interaction - for example how fast the client turns up or down the heat in the shower.

We use video to illustrate the behavior of the system. Video is a realistic medium, and the images cause a greater emotional impact on the user than straight statistics or graphs showing that the temperature curve rising. The intention is to increase the client's motivation and understanding of results. In the first stage of prototyping, still images were used. When the programming and linking with Powersim Studio is further elaborated, the still images will be replaced by similar video clips. There will then be two versions of the model: one video version and one with still images.

A longer model generated sequence passing through changing temperatures may look like this (Fig. 4.1):

By using short clips as building blocks for model-generated videos, it was not necessary to film and preedit large number of sequences, representing all possible simulation outcomes. Instead a library of single clips was generated that could be combined in numerous ways creating different 'stories'. Classic conti-

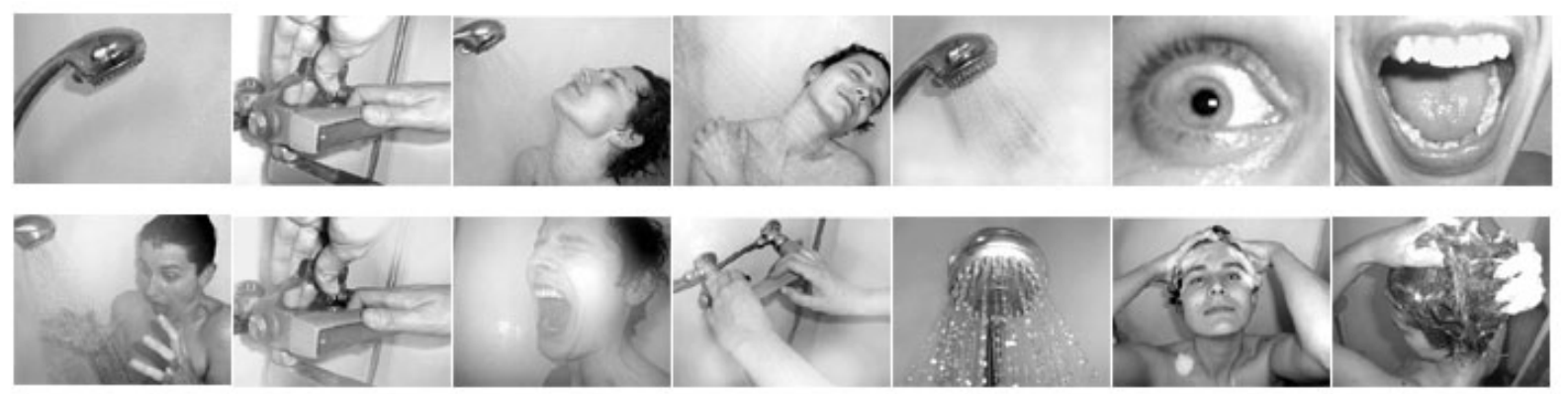

Figure 4.1: Example of model-generated sequence 
nuity editing techniques were used in order to create a cohe rent story from several individual clips (see, for example, Bordwell and Thompson, 1986).

The framing of the stills/ video clips is inspired by the famous shower scene in Alfred Hitchcock's Psycho, where the main female character is never seen in long shot. The scene is composed of close-ups and shoulder shots edited together in an accelerating rhythm. What causes screams and drama in the shower model is however not a Mr. Bates, but scolding hot or ice-cold water.

As long as the shower temperature remains unchanged, the generated sequences would enter a loop. If the shower temperature stays pleasant, the following pictures/ clips could loop (Fig. 4.2):

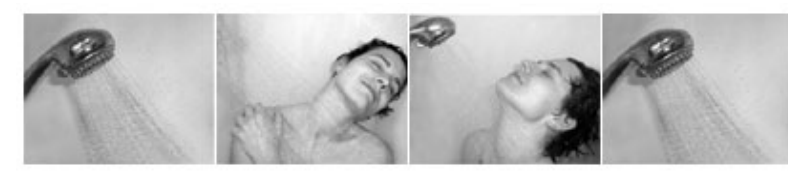

Figure 4.2: "ok temperature" loop

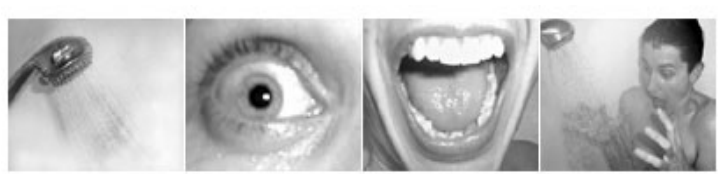

Figure 4.3: "too hot water" loop

For very hot water, a different sequence would be activated (as seen in fig. 4.3). For dramatic effect, the clips should be shorter in duration, in contrast to the clips in the more relaxed 'ok temperature' sequence (Fig. 4.2).

The "too hot water" sequence would continue in a loop until the user does something to try to change the temperature. However, the sequence continues with a "still-hot-water-loop" until the temperature actually changes.

New temperature loops (for example shifting from 'ok' temperature to 'too

cold') will always start with a "neutral" image, called cutaways in editing language, such as a close up of the showerhead (Fig. 4.4), or the hands changing the temperature tap when the user does the same thing in the learning environment (Fig. 4.5).

In this way (when using video clips) sudden shifts in mood is avoided when the temperature does not shift abruptly (as seen in fig. 4.6). The result will be a continuous 'story' unfolding as the simulation unfolds.

\section{Client Learning Strategies}

Verbal explanations of the model, visualization with movies and animation of the interaction and changing of the models elements (animation of the

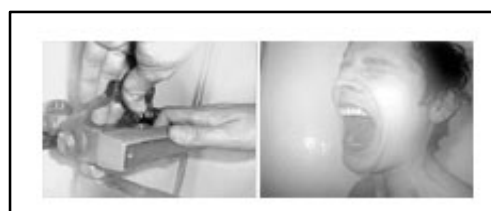

Figure. 4.5: Cutaway

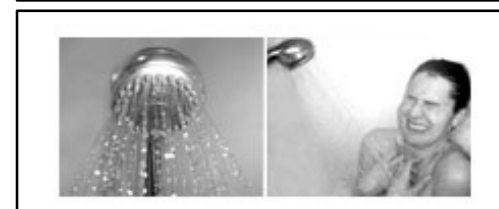

Figure. 4.4: Cutaway

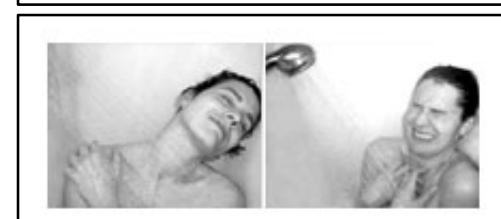

Figure. 4.6: Jump cut pipe system) are examples of what Reigeluth and Scwartz (1989) call "the instructional overlay" of a simulation model (Alessi, 2000: 181). The instructional philosophy behind our approach to the ILEversion of the two-shower model is discovery learning coupled with expository learning elements (see Alessi, 2000; Alessi \& Trollip, 2001).

The user/ client should try to find out herself how to manage the system - the shower temperature through trying and failing. The feedback provided through the shower video sequences is "natural" corresponding to the feedback one would receive in a real-life environment, without suggesting any solution to the problem (discovery learning). However, the user is introduced to the problem first, through the presentation of the problem scenario, and throughout the program, help is available from the hotel receptionist (a sound file available if clicking the phone-icon (Fig. 3.3)) or the pipe system animation (expository learning). The shower model illustrates the consequences of delay in awareness; the difference between being aware of/ not aware of how the system works (delays etc). The oscillations of the temperature for the two showers will initially be symmetrical: In the beginning the persons showering 
will react quite similarly to changes in the system, and both have the same goal: a certain temperature. The intuitive response for both would be to turn up the heat when it is too cold, and turn down if it becomes too hot. The consequence of their unawareness/ behavior is that none of them will reach their goal.

The user must develop an understanding of how the underlying structure (the pipe system) renders control of the temperature difficult. There is a delay from a change is made in the tap setting until the water with the new temperature reaches the showerhead. Eager to obtain the right temperature, the user may exaggerate the changes in the tap setting, disregarding the delay in the system. In addition, the user's access to the hot water resource depends on the tap settings of both showers. If the user turns the tap extremely high, the other showering person's (played by the computer or another user in a two-user model) access to the hot water is restricted, and her temperature sinks. The second showering person will then turn her tap setting up, which again influences the amount of hot water that the first user has access to. Controlling the system based on previous experience is difficult, because the same tap setting will not always result in the same temperature.

Morecroft et al. suggest that in a two-shower model situation the person taking a shower might react differently if she is aware of the temperature in the other shower, and they model this scenario with a "mutual awareness index" of 0.5 (1995:299-300). In our model, when played by two players, the players can themselves see if they behave differently when the peephole from the other shower is activated, and if they manage to find a policy that bring them to their goal - a certain shower temperature - in a shorter time. An enduring comfortable temperature for both showers is only feasible when the users are aware of each other. The other showering person's reactions and the system structure must be taken into account when changing tap setting. A shared understanding of the underlying structure and its effect on the behavior of such a system is therefore necessary in order to control it.

Through the visualization (video from the showers and animation of the pipe system) important characteristics of the system may be communicated to the user and help them reach a shared understanding of how the system works. Rather than displaying the mathematical equations of the model, they are represented by images that are easier for the human mind to conceive. Information may be visualized by converting data to a visual form that employs human perception skills and abilities in interactive manipulation (Card, Shneiderman, \& Mackinlay, 1999). In the Two-Shower Model, we have chosen not to reveal the underlying stock and flow diagrams in the simulation, but instead to make the underlying model visible to clients by using animation of the plumbing. The complex stock and flow diagrams are not easily understood by novices in system dynamics, and are probably more confusing than instructive.

Instructional simulations are often classified as conceptual - teaching about something, or procedural - teaching how to do something, or a combination of both (Andersen, 1980; see also Alessi \& Trollip 2001; Alessi, 2000). Even if the user in a certain way learns how to manage the temperature in a twoshower system scenario, the conceptual part of the simulation is where the important part of the learning should be. The Two-Shower Model is a metaphorical model and the intention of the learning environment is to teach the client about the system and the consequences of interdependence in resource allocation.

For clients, the shower-model is replaced by a real-life scenario - a factory floor, a personnel system, stocks and flows of wares etc. The shower-model however is useful for clients for understanding systems as well as in-house training.

\section{A Second Model: The Nile Valley}

A second example of a model developed for a client within the VOCS project is a prototype of the Nile Basin Valley. The client here was the Information and Decision Support Center of the Egyptian Cabinet in Cairo. 
The model was developed through discussions with the former Egyptian Ambassador to Norway, Magdy Hefny, in order to show how visualized system dynamics modeling could be used as a tool for intercountry planning of water resources. The figure below (Fig. 5) shows a simple graphic interface showing the effect of industrial development and pollution on shared waterways. A fully developed model would allow for use of video material presenting a narrative on the changes to the water levels and effects on life along the river, with use of characters similar to the shower-model.

The graphic interface here is, as far as accessibility is concerned, a step beyond that of traditional modeling. Behind this interface is the possibility for each client to add statistical variables to the individual factors.

The model was to involve four countries seeking to find forms of sustainable development. The two upstream countries both receive financial support from outside sources (development aid) in which to develop their resources.

Country A1 was receiving assistance from a country with expertise in dam-building and cement. Dambuilding was to ensure the development of industry through the supply of regular electricity supplies. The result from the dam-building was the increase of industrial waste and major changes to water levels as water was released or retained in the dam.

Country A2 in this model was receiving support from a country with a developed fertilization industry and therefore provided assistance in this form. Factors effecting the waterways here and downstream were then silt through deforestation and high fertilization content in the water leading to the growth of water plants that clogged downstream bays and ports.

Country B was experiencing a period of major civil unrest and therefore was receiving little support for the development of industry or agriculture. Assistance was aimed primarily at health and housing of refu-

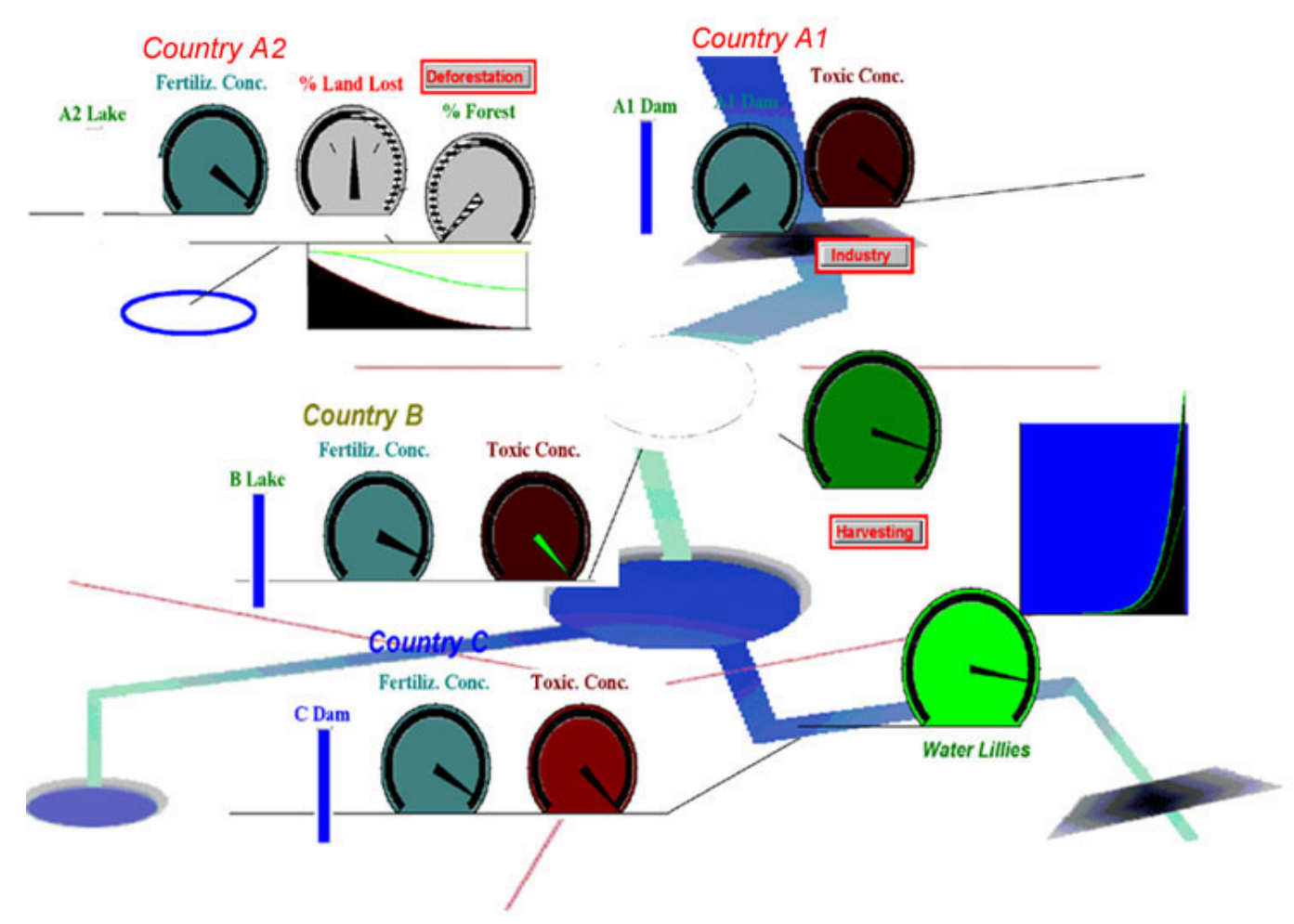

Figure 5: Interface Nile River Model 
gee populations. The country is affected heavily however from upstream industrialization and increased agriculture.

Country $\mathrm{C}$ is a more developed country with industry and agriculture balanced to the traditional water supply and quality. As with country B, however, this country's water supply was being affected heavily by changes upstream.

The client's needs then are a tool with which either single or multiple users can change the ind ividual variables - fertilization, water release, pollution etc. - to find a balance in development and pollution levels that all receptors find acceptable. In other words, ideally a tool for use in diplomacy and with which donor countries can balance the needs perceived in individual countries with factors effecting whole regions.

The model has so far only been developed to the prototype stage.

\section{A Third Model: Quito}

A final model uses the city of Quito, Ecuador, as case study. The 'client' for this project were city planners, who could use the model as a presentation tool to explain policies and consequent scenarios to authorities and the city's inhabitants. The project was developed for, and presented at the UNESCO World Heritage Center 30th Anniversary Virtual Congress (Skartveit, Goodnow \& Viste, 2002).

The Quito model, as the previous models described, uses system dynamics simulation modeling enhanced with multimedia, including non-linear video. The main advantage of using System Dynamics in urban planning is that it allows experimenting, enhances understanding of the interconnectedness of elements in a system and encourages long-term thinking and planning. There exist many examples of simulation models built for use in urban planning and management. In the construction of the Quito prototype we are drawing on examples both from pure system dynamics models such as Jay W. Forrester's Urban Dynamics (Forrester, 1969), learning environments, interactive documentaries, commercial games such as SimCity (Electronic Arts, 2002, 1996), as well as GIS visualization techniques.

\section{The City of Quito}

Quito, being both an historic and a modern city, faces the challenges of mixed use: a city for locals, tourists, different social groups, commerce and housing. In a first, simplified prototype we have focused on a selection of issues that are frequently listed as problem areas for the historic center of Quito and subject of planning and future regulations:

- Traffic: The narrow streets of the colonial center are often congested with cars and heavy vehicles such as old buses, causing pollution of air and buildings, as well as noise.

- Unorganized street sellers - 'vendedores ambulantes': The street sellers are mainly poor people, offering food and products to by-passers from improvised stands. This unorganized commercial activity contributes to the lively character of the historic center, but is also considered to cause chaos and disorder such as garbage left on the streets by the end of the day, blocking of sidewalks and smoke from preparation of food using charcoal.

- Security: At night some parts of the historic center are considered insecure, due to incidents of crime and violence.

- Maintenance: Many of the old houses of the historic center are in poor shape because of lacking maintenance and renovation. 
All simulation models are simplified representations of real systems. The level of simplification depends on the purpose of the model and the needs of the client. In the first stage of prototyping for the Quito model we have concentrated on the visualization aspect, and reduced the comple xity and fidelity of the underlying system dynamic model.

\section{Use of Video Images and Animation in the Quito Model}

We have chosen to represent the city of Quito with a map (Fig. 6). When the user changes variables in the model, and press "run simulation", the development is shown with animations on the map.

Expanding or diminuishing colored areas or dots represent increasing or decreasing rates of pollution, number of streetsellers, etc.

In addition to animation, this model also uses video to illustrate the behavior of the system. The video clips are activated using the same technique as in the twoshower model: The underlying simulation model (and the user's interaction with it) will generate short video sequences representing the actual conditions of the system. As the simulation unfolds, short running video clips (20-30 $\mathrm{sec})$, called up from a library of clips, will pop up as feedback. The video clips work as comments on the simulation results, showing for example what consequences the user's choices might have for the citizens. We implemented the videos so that they would not interrupt simulations. The video clips keeps

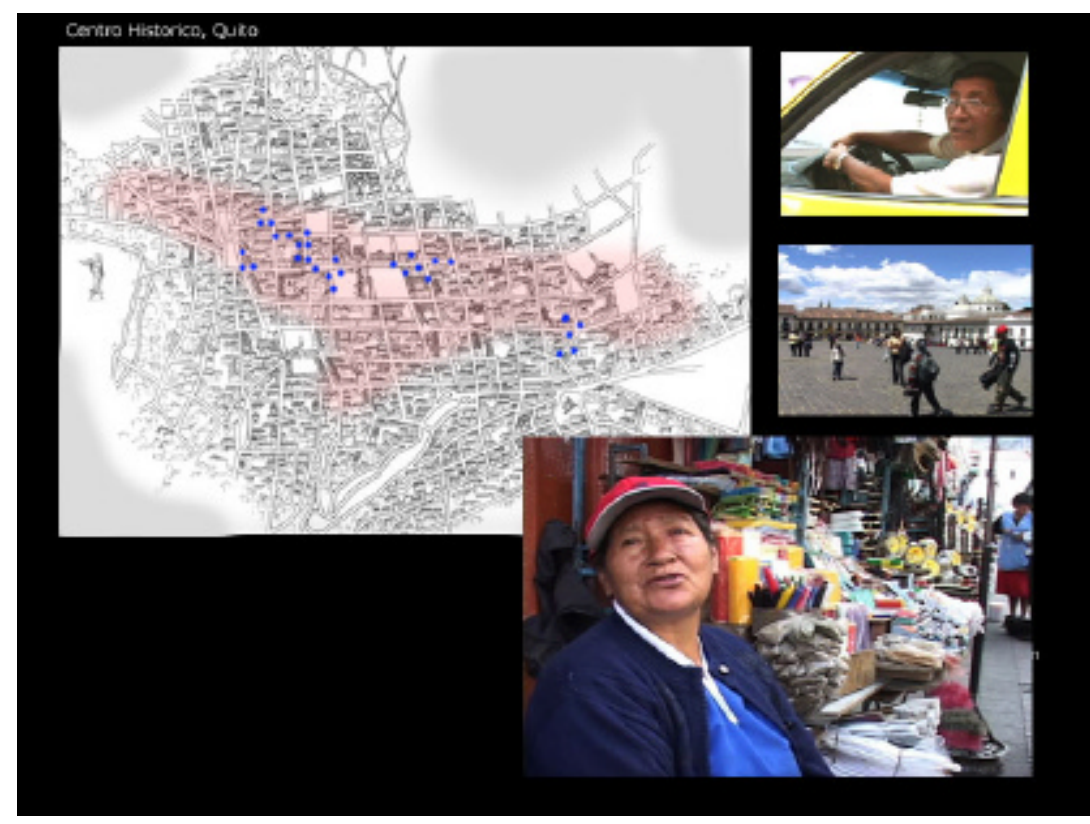

Figure 6: Screenshot with map animation and a video-clip selected.

appearing and disappearing on one side of the screen, unless the user chooses to take a further look at them. The user can select the clips that pop up to pause the simulation and replay the clips in a higher resolution and more centrally placed (in the lower right part) on the screen (Fig. 6).

Video can present aspects of reality that is not easily quantified as a number in a model. For example in the Quito model, we could have parameters that indicate the degree of welfare of the street sellers as a group, but a video clip with the response of one individual street seller telling how a displacement would affect her personally, would be a more illustrative way to show the consequences of a policy. Again, this would depend on the client's needs. If the client wishes to use the model for public awareness campaigns or for political interventions, different stories wo uld be added.

In the first versions of SimCity (Electronic Arts 1996), the inhabitants of the cities simulated in the game, ' the Sims', are represented in an anonymous way. In GIS visualizations, population groups are normally represented as colors or dots. UNESCO focuses the importance of including the needs of often marginalized habitants of historic cities in urban planning. Video testimonies is an often used device in documentary and news footage to personalize a story. In the Quito prototype the video testimonies are intended to give the audience a better understanding of the situation of individual citizens - or, rather, give voice to individual representatives of different groups of citizens and allow them to become more than a number in a model. 
In addition to the emotional aspect, another advantage of using video in instructional programs is that visual information is often remembered more easily (Alessi \& Trollip, 2001). It is important to emphasize, however, that the user can choose whether to receive the video feedback or not. Since the running video clips require higher speed and memory, the model without video could also be used by clients in low-end environments.

With the video feedback activated, the model takes the character of an interactive documentary, where the Quito that is presented is dependent on the user's interaction and choices. Aspects of complex systems and connections could also be presented in a regular documentary or TV program, but through simulation, the user must figure out these connections herself, through experimenting with the model.

\section{The Intended Client}

The intention behind the Quito model was to create a heritage management tool that could be used not only for planning, but also as a presentation tool for developers and planners. Traditional non- visualized system dynamics simulation models have i.e. been used in business management training to help managers understand the complexity and workings of their organizations. However, many of these models require the client to go through a time demanding introduction to System Dynamics. The Quito model is intended for users without such skills. Urban planners without knowledge of System Dynamics could then use the model as a management tool to test policies and present the problem and possible results of different policies to authorities or investors. By running simulations, the developers could illustrate and explain to their clients what effects different policies are expected to generate. As a presentation tool, the video visualizations would be particularly useful to illustrate in a vivid way the effects of policies on the population or the city environment.

One could also imagine a scenario were the tool was available to interested citizens on public computers, for instance in public libraries, House of Culture or in Universities. Its public use might generate discussion among citizens on urban development and future scenarios for the city. Another example of public use of the model could be to apply it in schools, especially the public schools of areas where the children are directly affected by problems treated in the model, such as pollution. For most public schools in Latin American cities such as Quito, this would imply funding to ensure computer access. However, working collaboratively in groups, only a few computers would be needed per school. The aim of using the model in educational contexts would not so much be the elaboration of complex development plans, but to use it as a tool to create discussion and awareness of problems, consequences and possible solutions, and raising citizen consciousness. The interface, where results are displayed through video images and color animations instead of graphs and numbers, makes the model accessible and engaging for a wider range of users than just professional city planners.

\section{Further Development of the Model}

A further step in the development of this and similar prototypes, would be to let the user/ client not only observe the behavior, but also be able to backtrack her choices and find out what caused the behavior. For this we imagine a "why button" that would take you back through the decisive points in the simulation history or trace the origin of a particular development. The explanation would be presented as a model-generated story, after the formula "A lead to B and this caused C to...". The possibility for the client not only to observe the behavior of the system - the simulation results - but also get her choices analyzed through the back-tracking mechanism, should enhance learning and understanding.

\section{Model Validation and Bias}

Model validation and bias is an important subject of discussion within the system dynamic field (see for example Sterman, 2002). No model can be an accurate, objective representation of reality, nor should it pretend to be so. A simulation model will always be a representation based on the modelers' assump- 
tions. This should be reflected upon when developing simulation models representing real systems, especially when used in education and as a tool for real life planning (for a discussion of subjectivity in simulation models in general, see for example Crawford, 2002 or Starr, 1994).

A discussion of validation is therefore necessary when utilizing system dynamic models as planning tools. The models may be used as a basis for decisions that have substantial effects on the surroundings. Basing decisions on models that are of insufficient quality to serve their purpose may create considerable negative consequences. However, producing true copies of reality is impossible. The system that is modeled is in itself an open system with no set boundary. It is a segment of a vast system of interconnected variables. Establishing the exact system structure and predicting the exact system behavior is therefore infeasible (Oreskes, Schrader-Frechette \& Belitz, 1994).

Making decisions based on a model may give a different result than expected because there are variables in the real, open system that affect its behavior, but that are not considered in the model of the system. Determining the model boundary is therefore a crucial but difficult task when constructing a system dynamic model (Sterman, 2000). Since the system is open, and no boundaries exist in reality, the modeler must decide where to set the model boundaries, what to include and what to omit. In determining the model boundary and selecting which variables to include, the subjectivity of the modeler becomes part of the model. The model boundary is influenced by the domain knowledge and preconceptions of the modelers, the incentives for building the model, and the people and actions surrounding the modelers. It is impossible to declare complete validity of a system dynamic model, since the model is a relatively subjective abstraction of a segment of a real system.

Though the modeling and validation process is influenced by subjectivity, and a correct model is impossible to construct, guidelines of how to assess the model are necessary. One approach is to look at the usefulness of the model (Barlas, 1996). The purpose of making the model is to solve some kind of problem. The usefulness of the model can be assessed by how well the model solves the problem. The assessment of the model should therefore be performed; keeping in mind how well the model serves its purpose, i.e. solves the problem.

In system dynamic modeling much of the validation takes place during the modeling process (Balci, 1995). This validation is done mainly informally without documentation. However, formal tests are also necessary, as more and more confidence in the model may be accumulated as these tests are passed (Forrester \& Senge, 1980). Several tests of the model structure, the behavior, and the relationship between structure and behavior are proposed for system dynamic models (Barlas, 1996; Richardson \& Pugh, 1981). Barlas presents three categories of tests. Direct structure tests compare the structure of the model to observations of the real system or literal descriptions of the system. Structure oriented behavior tests assess the structure of the model indirectly by applying tests that should generate certain behavior. Behavior pattern tests aim to test the correspondence between model behavior and data gathered from the system.

The projects described in this paper have mainly been concerned with visualization issues. If the models are implemented as part of a decision environment, extensive testing must be performed. Some formal tests are already carried out, such as extreme conditions analysis of the Quito model. This analysis involves assigning variables extreme initial values, such as for example setting the population level to 0 . The test checks whether the birthrate, the death rate, and the population level remains 0 throughout the simulation (unless there for example is an immigration rate). Sensitivity analyses that test the behavioral sensitivity in response to changes in input were also performed.

In the validation process, it is important to include modelers, decision-makers, and experts in order to secure that the testing process includes people with expertise within various fields and interests in model results. In a validation of the Quito Model it would be necessary to involve city planners to assess assumptions about the effect of different renovation policies on social economic variety in neighborhoods. 
Further, experts on air contamination may be brought in to evaluate parts of the model describing pollution from traffic and cooking by street vendors. Another set of experts may be brought in to evaluate the effect of air contamination on building deterioration. The participation of modelers is also necessary to ensure that modeling issues and solutions are taken into account.

The validation process should not end when a model is considered finished and implemented as part of a decision environment. Since a model is a subjective representation of reality it is important to be critical in the use of the model, and keep in mind the model assumptions when used as a basis for decisions affecting the real system. It is especially important to remind or inform clients and inexperienced users of such models of their limitations.

\section{Technical Implementation}

The prototypes developed in this project could be described as models where the underlying system dynamic model represents a 'skeleton' - 'dressed up with' a multimedia interface, or a story-engine generating multimediated stories. The flow of data between the underlying system dynamic model and the multimedia interface is being controlled by additional software.

In both the shower model and the Quito model we have used Powersim Studio SDK as the simulation engine and Macromedia Flash MX for the user interface. Powersim SDK offers two related interfaces to the model, one purely COM based (directly usable by $\mathrm{C}$ and $\mathrm{C}++$ compilers that support COM) and an ActiveX controller built on top of the COM interface. The model in Powersim SDK contains only the mathematical equations of the model, and performs the numeric integration of the differential equations in the model. Flash contains the graphics and video clips of the model, and visualizes the model behavior through multimedia objects such as video, sound, and graphics. Flash enables the user to interact with the model. However, communication between Powersim and Flash is necessary in order to give input to the model, and to change the user interface based on the behavior of the model. Therefore a small program that enables communication between Powersim and Flash is made in Visual Basic 6.0. This small program loads the ActiveX components and control their execution. It also provides data from the model to the Flash component so that the visualization of the user interface can be determined. It also retrieves data from the user interaction in Flash, and changes the variables in the Powersim model accordingly.

Shortly, the interface of the Quito model will be implemented directly into the next version of Powersim Studio through ActiveX controllers. This will simplify the process of connecting Flash and Powersim and will have a positive effect on performance. However, the final goal is that the features developed in the user interfaces for the prototypes, such as a model-script for the integration of multiple video screens to illustrate behaviour, will be implemented as a feature in new versions of the Powersim software.

\section{Conclusions}

System dynamics attempts to analyze and model the many complex and invisible systems - human, ecological, and industrial systems - that we depend upon. Data presentation and visualization will be a critical arena for future system development in order to communicate the system dynamics insights to a broader audience (Sterman, 2000). The VOCS project and the prototypes described in this paper explore ways to communicate these insights to clients. By making the system dynamic models more transparent and accessible, simulation models can be used in interactive learning environments and as planning tools in schools, universities, government agency, diplomacy, and bus iness.

Further research involves prototype testing, to find out how the proposed techniques work for different audiences.

In the further development of the prototypes described in this paper, we will also explore how the link between structure and behavior can be explained to clients through visualization. We wish to develop a 
backtracking feature that identifies dominating feedback-loops and takes the user back through the decisive points in the simulation history or trace the origin of a particular development. The images illustrating the behavior in the current prototypes could be re-used together with graphics, creating stories that explain what happened.

While most simulation games are black box simulation where the underlying model remains hidden, most system dynamics software display the underlying model directly through equations and complex stock and flow diagrams that are not easily understood by inexperienced users. We envision that the relationship between structure and behavior in a model can be explained and illustrated in a more comprehensible way by applying appropriate visualization methods. Such visualized models may then help clients to acquire a deeper understanding of system dynamics models, and enable them to evaluate a particular model's underlying assumptions and its usefulness or limitations as a planning or information tool.

\section{References}

Alessi, S. M. (2000). Designing educational support in system dynamics based interactive learning environments. Simulation \&Gaming, 31 (2), $178-196$

Alessi, S. M. \& Trollip, S. R. (2001). Multimedia for learning. Massachusetts: Allyn \& Bacon

Andersen, J.R. (1980). Cognitive psychology and its implications. San Francisco: Freeman

Balci, O. (1995). Principles of simulation model validation, verification, and testing. International Journal in Computer Simulation, 1995.

Barlas, Y. (1996). Formal aspects of model validity and validation in system dynamics. System Dynamics Review, 12(3), 183210.

Bordwell, D. \& Thompson, K. (1986). Film art: An introduction. New York: McGraw Hill

Card, S. K., Shneiderman, B., \& Mackinlay, J. D. (1999). Readings in information visualization: using vision to think. San Francisco: Morgan Kaufmann.

Crawford, C. (2002). Subjectivity and simulation. Publication from the Foresight and Governance Project at the Woodrow Wilson Center, Washington, DC, 2002.

Electronic Arts (1996) SimCityClassic [computer software] Walnut Creek, CA.

Electronic Arts (2002) SimCity3000 [computer software] Walnut Creek, CA.

Forrester, J. W. (1961). Industrial dynamics. New York: John Wiley and Sons.

Forrester, J. W. (1969) Urban dynamics. Cambridge, Mass.: The MIT Press.

Forrester, J. W., \& Senge, P. M. (1980). Tests for building confidence in system dynamics models. System Dynamics 14, 209-228.

Frasca, G. (2001). Video games of the oppressed: Video games as a means for critical thinking and debate. Master's thesis at Georgia Institute of Technology. Retrieved January 3, 2002 from http://www.jacaranda.org/frasca/thesis

High Performance Systems (1994). STELLA [computer software]. Lyme, NH.

Monus, P., Kuenzli, D., \& Griffith, J. (2000). The role of supervisors in improvements dynamics between 3 leadership processes in building internal commitment and worker empowerment. Paper presented at the 2000 Annual Refinery \& Petrochemical Plant Maintenance Conference and Exhibition, Austin, Texas.

Morecroft, Larsen, Lomi \& Ginsberg (1995). The dynamics of resource sharing: a metaphorical model. System Dynamics Review 11(4), 289-309

Moxnes, E. (2000). Not only the tragedy of the commons: misperceptions of feedback and policies for sustainable development. System Dynamics Review, 16(4), 325-348

Oreskes, N., Schrader-Frechette, K., \& Belitz, K. (1994). Verification, validation, and confirmation of numerical models in the earth sciences. Science, 263, 641-646. 
Visualized System Dynamics Models

Pearce, C. (2002). Sims, BattleBots, Cellular Automata God and Go. A conversation with Will Wright. Gamestudies, 2 (1). Retrieved January 3, 2003 from http://www.gamestudies.org/0102/pearce/

Powersim. (1999). Powersim. [computer software]. Bergen, Norway.

Reigeluth, C. M. \& Schwartz, E. (1989). An instructional theory for the design of computer-based simulations. Journal of Computer-Based Instruction. 16 (1), 1-10.

Richardson, G. P., \& Pugh, A. L. (1981). Introduction to system dynamics modeling. Portland, Or.: Productivity Press.

Sawyer, B. (2002). Serious games: Improving public policy through game-based learning and simulation. Publication 2002-1, the Foresight and Governance Project at the Woodrow Wilson Center, Washington, DC, 2002

Starr, P. (1994). Seductions of Sim. The American Prospect, 5 (17) (1994, March 21). Retrieved February 1, 2003 from http://www.prospect.org/print/V5/17/starr-p.html

Skartveit, H-L., Goodnow, K., \& Viste, M. (2002). 'SimHeritage': Multimedia and system dynamics in learning tools for heritage management. In proceedings from the UNESCO World Heritage Center 30th Anniversary Virtual Congress WORLD HERITAGE IN THE DIGITAL AGE. Mexico City, Nov. 6 - 8. 2002: http://www.virtualworldheritage.org/index.cfm?pg=PapersProjects\&l=en\&confSelect=Mexico

Sterman, J. D. (1989). Modeling managerial behavior - Misperceptions of feedback in a dynamic decision-making expeniment. Management Science, 35(3), 321-339.

Sterman, J. D. (2000). Business dynamics: Systems thinking and modeling for a complex world. Boston: Irwin McGraw-Hill.

Sterman, J. D. (2002). All models are wrong: Reflections on becoming a systems scientist. System Dynamics Review, 18(4), 501-531.

\section{Biographies}

Hanne-Lovise Skartveit is a PhD student at InterMedia and the Department of Media Studies, University of Bergen. She holds a Masters degree in Screenwriting from the University of Bergen, Norway.

Dr. Katherine J. Goodnow is Associate Professor at the Department of Media Studies, University of Bergen, and Head of Programme for the Masters degree in Screenwriting for Film, Television and Multimedia. Goodnow completed her undergraduate degree at the University of Technology, Sydney, Australia, and Masters and Doctoral studies at the University of Bergen, Norway. Research work is oriented to questions of new media, representation, identity, documentary and narrative studies.

Magnhild Viste is a PhD student at InterMedia and the Department of Information Science, University of Bergen. She holds a Masters degree in System Dynamics from the University of Bergen, Norway. 